\title{
Clonality analysis of lymphoid proliferations using the BIOMED-2 clonality assays: a single institution experience
}

\author{
Ira Kokovic ${ }^{1}$, Barbara Jezersek Novakovic², Petra Cerkovnik¹, Srdjan Novakovic ${ }^{1}$ \\ ${ }^{1}$ Department of Molecular Diagnostics, ${ }^{2}$ Department of Medical Oncology, Institute of Oncology Ljubljana, Ljubljana, Slovenia
}

Radiol Oncol 2014; 48(2): 155-162.

Received 9 May 2013

Accepted 1 October 2013

Correspondence to: Prof. Dr. Srdjan Novaković, Institute of Oncology Ljubljana, Zaloška 2, 1000 Ljubljana, Slovenia. Tel: +386 15879432 ; Fax: +386 15879 410; E-mail: snovakovic@onko-i.si

Disclosure: No potential conflicts of interest were disclosed.

Background. Clonality determination in patients with lymphoproliferative disorders can improve the final diagnosis. The aim of our study was to evaluate the applicative value of standardized BIOMED-2 gene clonality assay protocols for the analysis of clonality of lymphocytes in a group of different lymphoid proliferations.

Materials and methods. With this purpose, 121 specimens from 91 patients with suspected lymphoproliferations submitted for routine diagnostics from January to December 2011 were retrospectively analyzed. According to the final diagnosis, our series comprised 32 cases of B-cell lymphomas, 38 cases of non-Hodgkin's T-cell lymphomas and 51 cases of reactive lymphoid proliferations. Clonality testing was performed using the BIOMED-2 clonality assays.

Results. The determined sensitivity of the TCR assay was $91.9 \%$, while the sensitivity of the IGH assay was $74.2 \%$. The determined specificity of the IGH assay was $73.3 \%$ in the group of lymphomas and $87.2 \%$ in the group of reactive lesions. The determined specificity of the TCR assay was $62.5 \%$ in the group of lymphomas and $54.3 \%$ in the group of reactive lesions.

Conclusions. In the present study, we confirmed the utility of standardized BIOMED-2 clonality assays for the detection of clonality in a routine diagnostical setting of non-Hodgkin's lymphomas. Reactions for the detection of the complete IGH rearrangements and reactions for the detection of the TCR rearrangements are a good choice for clonality testing of a wide range of lymphoid proliferations and specimen types while the reactions for the detection of incomplete IGH rearrangements have not shown any additional diagnostic value.

Key words: BIOMED-2; clonality analysis; lymphomas; IGH rearrangement; TCR rearrangement

\section{Introduction}

In the majority of patients with suspected lymphoproliferations (LP), the diagnosis can be done by histomorphology or cytomorphology, supplemented with immunohistochemistry or flow cytometric immunophenotyping. ${ }^{1}$ However, in 5-15\% of patients the morphological and immunophenotypic features are not typical and the diagnosis is more complicated. In such cases, molecular clonality analysis of lymphocyte populations may contribute to the diagnosis. ${ }^{1,2}$ Clonality analysis of lymphoid cells using the polymerase chain reaction (PCR) to amplify V-(D)-J junctional regions of im- munoglobulin (Ig) and T-cell receptor (TCR) genes enables the discrimination between polyclonal, reactive processes and monoclonal, malignant tumors. ${ }^{1-3}$ Since the introduction of PCR-based assays in the early nineties, different strategies with different primer sets have been developed and used for determination of B and T-cell clonality. . $^{-12}$ However, many of those PCR-based clonality assays were designed to cover a limited number of possible $I g$ and TCR gene rearrangements, resulting in false negative results.,13

A comprehensive work of the European BIOMED-2 collaborative study group (now called the EuroClonality consortium) led to new stand- 
ardized PCR protocols with multiple primer sets for the clonality analysis of both $I g$ and TCR gene rearrangements in a diagnostic setting. ${ }^{14}$ In initial studies, novel BIOMED-2 multiplex PCR protocols were evaluated on large series of B-cell and T-cell malignancies, and histomorphologically reactive lesions. ${ }^{15-17}$ Based on their conclusions, the BIOMED-2 clonality assays were declared as highly sensitive, specific and reproducible, and thus reliable for detection of clonality in lymphoid malignancies. ${ }^{15-17}$ The guidelines for use of these assays in the routine clonality testing have been proposed. ${ }^{3}$ Recommendations for correct interpretation and potential pitfalls in the Ig/TCR clonality testing were also presented. ${ }^{18,19}$ Over the past decade, a number of studies have reported the successful application of the BIOMED-2 clonality assays in a diagnostic setting. ${ }^{20-38}$ Some studies have evaluated subsets of BIOMED-2 primers for clonality analysis in selected specimen types - fixed and decalcified bone marrow biopsies ${ }^{23}$, archival skin biopsy samples ${ }^{24}$, formalin-fixed and paraffin-embedded specimens ${ }^{26,29}$ and fine needle aspiration biopsies. ${ }^{27}$ The others applied BIOMED-2 assays to different disease sub-categories - B-cell precursor acute lymphoblastic leukemia ${ }^{21}$, classical Hodgkin's lymphoma ${ }^{26}$, follicular lymphoma ${ }^{28,29}$, cutaneous lymphoproliferations ${ }^{30}$, anaplastic large cell lymphoma and peripheral T-cell lymphomas $^{32}$, Mycosis fungoides and inflammatory dermatoses $^{33}$, polymorphous lymphoproliferative disorders in individuals with immunodeficiency conditions $^{34}$ and granulomatous disorders. ${ }^{35}$ Thus, the BIOMED-2 clonality assays have become the world standard for PCR-based Ig/TCR clonality testing. ${ }^{39}$ Moreover, the EuroClonality consortium recently developed a uniform reporting system for describing results and conclusions of Ig/TCR clonality assays. ${ }^{39}$

The aim of our retrospective study was to evaluate the applicative value of standardized BIOMED-2 gene clonality assay protocols for the analysis of clonality of lymphocytes on a series of various diagnostic specimens (fresh and formalinfixed) from Slovenian patients with different lymphoid proliferations.

\section{Materials and methods}

\section{Study group}

One hundred and twenty-one specimens from 91 patients with suspected non-Hodgkin's lymphoma submitted for routine diagnostics from January to
December 2011 were analyzed. Among diagnostic samples, bone marrow (BM) aspirates predominated (51), followed by formalin-fixed, paraffinembedded tissue specimens (FFPE) (31) and fineneedle aspiration specimens (FNA) (31). A minority of specimens consisted of cerebrospinal fluid (1), pleural fluid (4), imprint cytology of lymph node (1) and ascites (2). All specimens were subjected to cyto/histomorphological and immunophenotyping examination as well as to molecular clonality analysis of lymphocyte populations during routine diagnostic assessment.

\section{DNA isolation}

DNA from FFPE tissue specimens was isolated using the QIAamp FFPE tissue kit (Qiagen $\mathrm{GmbH}$, Hilden, Germany). DNA from other types of specimens was isolated using High Pure PCR Template Preparation kit (Roche Applied Science, Penzberg, Germany) according to the manufacturers' protocols. The concentration and the purity of DNA $\left(\mathrm{A}_{260 \mathrm{~nm}} / \mathrm{A}_{280 \mathrm{~nm}}\right)$ were determined using the Nanodrop spectrophotometer (ThermoScientific, Wilmington, USA).

\section{Clonality analysis}

Clonality analysis of lymphoid cells was performed using the BIOMED-2 clonality assays - ABI Fluorescence Detection (IdentiClone, InVivo Scribe Technologies, San Diego, CA, USA) according to the manufacturer's instructions. B-cell clonality was assessed using the IdentiClone IGH Gene clonality assay for detection of clonal rearrangements in the immunoglobulin heavy chain gene $(I G H)$. The T-cell clonality was assessed using the TCRB+TCRG Gene Clonality Assay for detection of clonal rearrangements in the T-cell receptor $\beta$ chain gene $(T C R B)$ and the $\mathrm{T}$-cell receptor $\gamma$ chain gene (TCRG).

The DNA quality was checked for all samples using the control gene PCR (Specimen Control Size Ladder master mix). The DNA was considered of adequate quality if amplified products of $\geq 400$ bp were obtained in a control PCR, except for the DNA from FFPE tissue, which was considered acceptable if amplified products of $\geq 300 \mathrm{bp}$ were obtained.

The IGH clonality was evaluated with five different IGH multiplex PCR reactions, three reactions for detection of the complete rearrangements $\left(\mathrm{V}_{\mathrm{H}}-\mathrm{J}_{\mathrm{H}}\right)$ and two reactions for detection of the incomplete rearrangements in the $I G H$ gene $\left(D_{H}-J_{H}\right)$ 
(V - variable, D - diversity, J - joining gene segments, respectively). The TCR clonality was evaluated with three TCRB and two TCRG multiplex PCR reactions. In case of doubtful results, the assays were repeated. Each run included monoclonal and polyclonal control DNAs for particular primer master mix, supplied with each BIOMED-2 clonality assay, and a contamination control (no template DNA in a reaction).

The fluorescently labeled PCR products were detected by capillary gel electrophoresis using the ABI 3500 Genetic Analyzer (Applied Biosystems, Foster City, CA, USA) and analyzed by fragment analysis. Amplified products from diagnostic samples were interpreted according to the manufacturer's instructions. Samples that failed to amplify following repeated testing were reported as "not detected" (i.e. clonality could not be detected due to insufficient quality or quantity of DNA for analysis).

\section{Final diagnosis}

The final diagnosis of each lymphoproliferation was set upon careful examination of all available information. Malignant lymphomas were classified according to the WHO Classification of Tumours of Hematopoietic and Lymphoid Tissues. ${ }^{40,41}$

\section{Sensitivity and specificity}

To determine the sensitivity and the specificity of IGH/TCR clonality assays we compared the results of molecular testing with the final diagnosis of each lymphoproliferation. The sensitivity of each clonality assay was calculated using the following equation: $\mathrm{TP} /(\mathrm{TP}+\mathrm{FN})$, in which $\mathrm{TP}$ represents the number of true positives and FN the number of false negatives. The specificity of each assay was calculated using the equation $\mathrm{TN} /(\mathrm{TN}+\mathrm{FP})$, in which TN represents the number of true negatives and FP the number of false positives. The specificities of IGH and TCR assays were calculated separately for T/B-cell lymphomas and for reactive lymphoproliferations.

\section{Results}

In the period from January to December 2011 we have analyzed 121 specimens from 91 patients (96 specimens were analyzed for IGH and 119 specimens for TCR clonality). Of these, 84 specimens were analyzed for both $-\mathrm{B}$ and T-cell clonality.
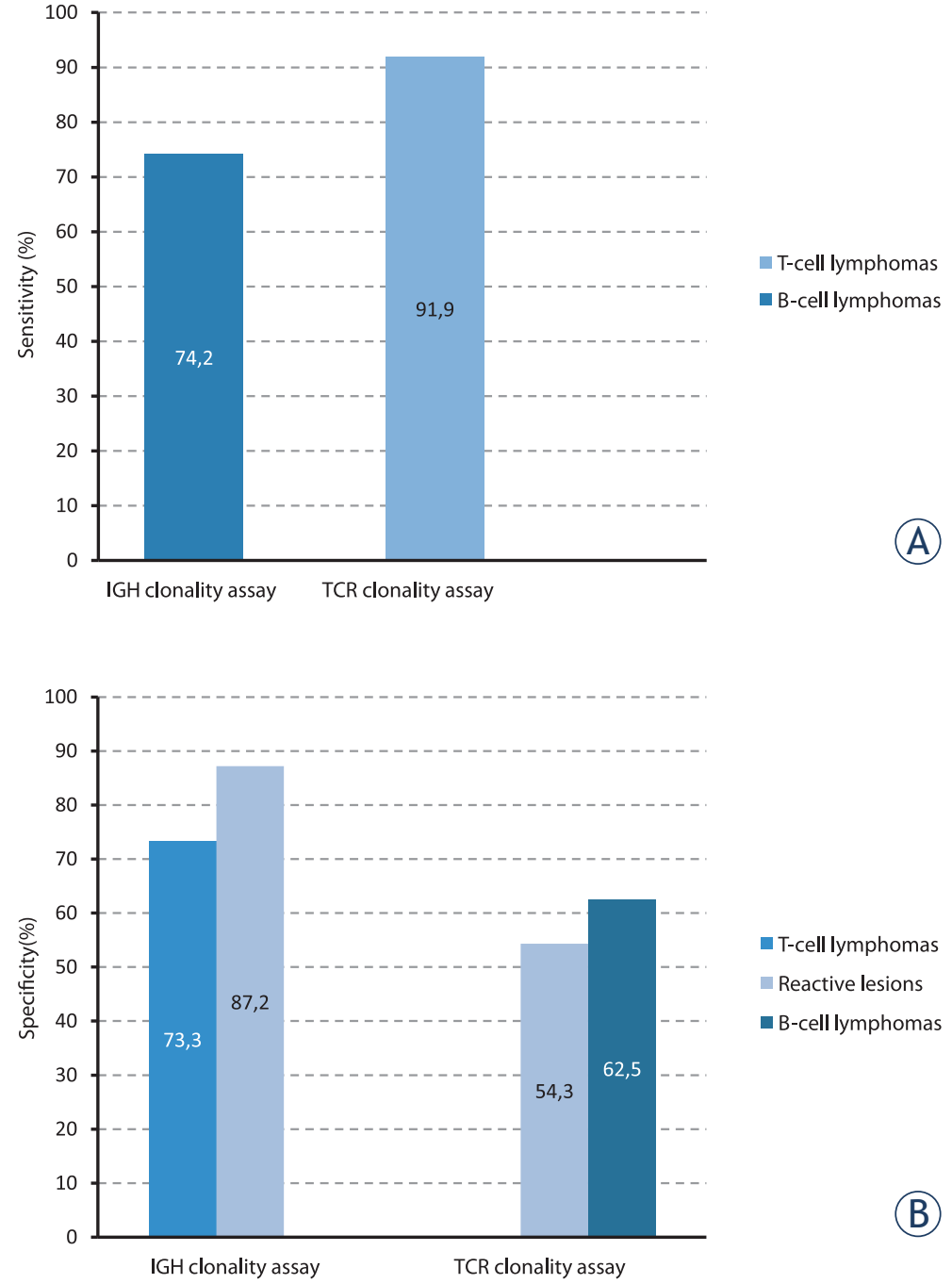

FIGURE 1. Sensitivity and specificity of the BIOMED-2 clonality assays determined in a group of T-cell lymphomas, B-cell lymphomas and reactive lesions.

To determine the sensitivity and the specificity of IGH/TCR clonality assays the results of molecular testing were compared with the final diagnosis of each lymphoproliferation.

The sensitivity of each clonality assay was calculated using the equation TP/(TP+FN); TP (true positives) - monoclonal (M) and "monoclonal in a polyclonal background" (M/P) results of the IGH clonality assay in a group of B-cell lymphomas, and $M$ and $M / P$ results of the TCR clonality assay in a group of T-cell lymphomas; FN (false negatives) - polyclonal (P) results of the IGH clonality assay in a group of B-cell lymphomas and $\mathrm{P}$ results of the TCR clonality assay in a group of T-cell lymphomas.

The specificity of the IGH clonality assay was determined separately for T-cell lymphomas and for reactive lesions. Similarly, the specificity of the TCR clonality assay was determined separately for B-cell lymphomas and for reactive lesions. The specificity of each assay was calculated using the equation TN/(TN+FP); TN (true negatives) - P results of the IGH clonality assay in a group of T-cell lymphomas or in reactive lesions, and $\mathrm{P}$ results of the TCR clonality assay in a group of B-cell lymphomas or in reactive lesions; FP (false positives) - $M$ and M/P results of the IGH clonality assay in a group of T-cell lymphomas or reactive lesions, and $M$ and $M / P$ results of the TCR clonality assay in a group of B-cell lymphomas or in reactive lesions. 
TABLE 1. Results of clonality analysis using BIOMED-2 clonality assays in suspected lymphoid proliferations

\begin{tabular}{|c|c|c|c|c|c|c|c|c|c|c|}
\hline \multirow{2}{*}{$\begin{array}{l}\text { Final diagnosis } \\
\text { (n) }\end{array}$} & \multicolumn{5}{|c|}{ IGH clonality } & \multicolumn{5}{|c|}{ TCR clonality } \\
\hline & $\begin{array}{c}M \\
(n)\end{array}$ & $\begin{array}{c}P \\
\text { (n) }\end{array}$ & $\begin{array}{c}M / P \\
(n)\end{array}$ & $\begin{array}{l}\text { ND } \\
(n)\end{array}$ & $\begin{array}{l}\text { NP } \\
(n)\end{array}$ & $\begin{array}{c}M \\
(n)\end{array}$ & $\begin{array}{c}P \\
\text { (n) }\end{array}$ & $\begin{array}{c}M / P \\
(n)\end{array}$ & $\begin{array}{l}\text { ND } \\
(n)\end{array}$ & $\begin{array}{c}N P \\
(n)\end{array}$ \\
\hline B-NHL (32) & 22 & 8 & 1 & 1 & 0 & 9 & 15 & 0 & 1 & 7 \\
\hline Reactive (51) & 6 & 41 & 0 & 2 & 2 & 20 & 25 & 1 & 0 & 5 \\
\hline TOTAL (121) & 32 & 60 & 1 & 3 & 25 & 61 & 43 & 3 & 2 & 12 \\
\hline
\end{tabular}

$\mathrm{B}-\mathrm{NHL}=\mathrm{B}$-cell non-Hodgkin's lymphoma; $\mathrm{T}-\mathrm{NHL}=\mathrm{T}$-cell non-Hodgkin's lymphoma; $\mathrm{M}=$ monoclonal; $\mathrm{P}=$ polyclonal; $\mathrm{M} / \mathrm{P}=$ monoclonal in a polyclonal background; ND = not detected; NP = not performed

According to the final diagnosis, our diagnostic series comprised 32 cases of B-cell lymphomas, 38 cases of non-Hodgkin's T-cell lymphomas and 51 cases of reactive lymphoid proliferations. The results of clonality analysis using BIOMED-2 clonality assays are shown in Table 1 . The calculated sensitivities and specificities of BIOMED-2 clonality assays after fragment analysis of amplified products are shown in Figure 1.

\section{The BIOMED-2 IGH clonality assay}

It was performed in 96 specimens (Table 2). In total, monoclonal IGH rearrangements corresponding to monoclonal B-cell proliferations were detected in 32 cases $(33.3 \%)$. Polyclonal IGH rearrangements corresponding to polyclonal B-cell proliferations were detected in 60 cases $(62.5 \%)$. One case of B-cell non-Hodgkin's lymphoma (B-NHL) was concluded as borderline ("monoclonal in a polyclonal background"). In three cases the B-cell clonality could not be determined either because of an insufficient number of B-cells in the specimen or due to the poor quality of the isolated DNA (in one case of histopathologically confirmed B-NHL and in two reactive specimens). Among B-cell lymphomas, 22 of 32 analyzed cases were monoclonal, representing "true positives" and 8 cases were polyclonal, representing "false negatives". Polyclonal IGH rearrangements in a group of B-cell lymphomas were detected in follicular lymphoma (FL) (3 cases), marginal zone B-cell lymphoma (MZL) (3 cases), diffuse large B-cell lymphoma (DLBCL) (1 case) and B-cell lymphoma with features intermediate between the DLBCL and Burkitt's lymphoma (BL) (1 case).

In the group of T-cell lymphomas, 11 of 15 analyzed cases were polyclonal by the IGH assay, representing "true negatives" and 4 cases were monoclonal, representing "false positives" - a case of T-cell lymphoma with monoclonal B-cell popula- tion and 3 specimens from a patient with angioimmunoblastic T-cell lymphoma (AITL) (2 FNAs and one BM aspiration). Among 51 specimens of reactive lymphoid proliferations (R), monoclonal IGH rearrangements were detected in 6 cases ("false positives") and polyclonal IGH rearrangements were detected in 41 cases ("true negatives").

\section{Incomplete rearrangements in the IGH gene}

Besides complete rearrangements in the IGH gene we also detected incomplete rearrangements $\left(\mathrm{D}_{\mathrm{H}^{-}}\right.$ $\mathrm{J}_{\mathrm{H}}$ ) in a few cases. In total, we detected 8 incomplete rearrangements in 96 specimens of LP analyzed by the IGH assay $(8.3 \%)$. Four were detected by the IGH-D reaction containing $\mathrm{D}_{\mathrm{H} 1-6}$ and $\mathrm{J}_{\mathrm{H}}$ primers (one in case of T-NHL and 3 in reactive lymphoid proliferations) and four by the IGH-E reaction containing $\mathrm{D}_{\mathrm{H} 7}$ and $\mathrm{J}_{\mathrm{H}}$ primers (one in case of $\mathrm{FL}$, one in case of T-NHL and two in reactive specimens).

\section{The BIOMED-2 TCR clonality assay}

It was performed in 109 specimens (Table 3). In total, by using the BIOMED-2 TCR clonality assay, the T-cells with monoclonal rearrangements were detected in 61 specimens, while T-cells with polyclonal rearrangements were detected in 43 cases. Borderline results ("monoclonal in a polyclonal background") were obtained in 3 specimens (two BM specimens taken for staging/follow-up of T-cell non-Hodgkin's lymphomas (T-NHL) and one FNA specimen with reactive lymphoproliferation). The T-cell clonality was not assessed in 2 specimens due to fragmented DNA (in one case of T-NHL and in one case of B-NHL). In a group of primary T-cell lymphomas, monoclonal TCRG and/or TCRB rearrangements were detected in 32 of 38 analyzed cases, representing "true positives". Three of 38 T-NHL cases were polyclonal by the TCR assay, 
TABLE 2. Detection of monoclonal /GH gene rearrangements in 96 specimens of lymphoid proliferations (LP)

\begin{tabular}{lc}
\hline Diagnosis & $\begin{array}{c}\text { No. of monoclonal } \\
\text { / No. of tested } \\
\text { specimens (\%) }\end{array}$ \\
\hline B-NHL - Primary tumor & $11 / 17(64.7)$ \\
MALT lymphoma & $1 / 2(50.0)$ \\
Follicular lymphoma & $3 / 4(75.0)$ \\
Diffuse large B-cell lymphoma & $1 / 2(50.0)$ \\
Marginal zone B-cell lymphoma & $2 / 4(50.0)$ \\
Lymphoplasmacytic lymphoma & $2 / 2(100.0)$ \\
B-NHL, unclassified & $2 / 3(66.7)$ \\
B-NHL - Staging/follow-Up BMa & $11 / 15(73.3)$ \\
\hline Total B-NHL & $22 / 32(68.8)$ \\
T-NHL & $4 / 15(26.7)$ \\
Reactive specimens & $6 / 49(12.2)$ \\
\hline TOTAL LP & $32 / 96(33.3)$ \\
\hline
\end{tabular}

B-NHL $=$ B-cell non-Hodgkin's lymphoma; T-NHL $=$ T-cell non-Hodgkin's Iymphoma; MALT Iymphoma = extranodal marginal zone lymphoma of mucosa-associated tissue; $L P=$ lymphoid proliferation

aBone marrow (BM) aspirates were taken from different patients with marginal zone B-cell lymphoma (4), diffuse large B-cell lymphoma (4) follicular lymphoma (3), MALT lymphoma (1), mantle cell lymphoma (1), plasmablastic lymphoma (1) and lymphoplasmacytic lymphoma (1).

representing "false negatives". Among T-NHLs polyclonal TCR rearrangements were detected in 2 cases of peripheral T-cell lymphoma, otherwise unspecified (PTCL-U) and in one case of peripheral T-cell lymphoma, cutaneous.

In the group of B-NHLs monoclonal rearrangements in TCR genes were detected in 9 of 25 analyzed cases ("false positives"). Fifteen cases of B-NHL had polyclonal rearrangements in TCR genes, as expected ("true negatives"). Among reactive lymphoid proliferations monoclonal TCR rearrangements were detected in 20 cases ("false positives") and polyclonal TCR rearrangements were detected in 25 cases ("true negatives").

\section{Discussion}

The aim of this study was to evaluate the application value of BIOMED-2 clonality assays for analysis of different lymphoid proliferations in the diagnostic setting. With this purpose, we analyzed 121 specimens from 91 patients with suspected lymphoproliferations. The clonality testing was performed using the BIOMED-2 clonality assays according to the guidelines proposed by the European BIOMED-2/EuroClonality group and the
TABLE 3. Detection of monoclonal TCR gene rearrangements in 109 specimens of lymphoid proliferations (LP)

\begin{tabular}{lc}
\hline Diagnosis & $\begin{array}{c}\text { No. of } \\
\text { monoclonal / } \\
\text { No. of tested } \\
\text { specimens (\%) }\end{array}$ \\
\hline T-NHL - Primary tumor & $22 / 26(84.6)$ \\
Peripheral T-cell lymphoma, unspecified & $12 / 15(80.0)$ \\
Peripheral T-cell lymphoma, cutaneous & $1 / 2(50.0)$ \\
Angioimmunoblastic T-cell lymphoma & $8 / 8(100.0)$ \\
Mycosis fungoides/Sezary syndrome & $1 / 1(100.0)$ \\
T-NHL - Staging/follow-up BMa & $10 / 12(83.3)$ \\
\hline Total T-NHL & $32 / 38(84.2)$ \\
B-NHL & $9 / 25(36.0)$ \\
Reactive specimens ${ }^{b}$ & $20 / 46(43.5)$ \\
\hline TOTAL LP & $61 / 109(56.0)$ \\
\hline
\end{tabular}

B-NHL = B-cell non-Hodgkin's lymphoma; T-NHL = T-cell non-Hodgkin's lymphoma

Bone marrow (BM) aspirates were taken from patients with peripheral T-cell lymphoma, unspecified (4), angioimmunoblastic T-cell lymphoma (3), T-lymphoblastic lymphoma (3), NK/T-cell lymphoma (1) and T-cell acute lymphoblastic leukaemia (1).

beactive specimens included 20 BM aspirates, 17 FNA specimens of lymph nodes and 9 FFPE specimens.

results of clonality testing were interpreted in the context of the final diagnosis.

\section{BIOMED-2 IGH assay}

The sensitivity as well as the specificity of the IGH assay in our diagnostic series of NHL cases was lower than expected. The sensitivity of the IGH assay in our diagnostic series was $74.2 \%$, while the BIOMED-2/EuroClonality group reported the sensitivity of $91.0 \%$, ranging from $85-100 \%$ depending on the disease category. ${ }^{3}$ Similarly, the determined specificity of the IGH assay was $73.3 \%$ in our NHL cases and $87.2 \%$ in the group of reactive specimens, again lower than reported in the BIOMED-2 study, where the overall specificity of the IGH clonality assay in T-NHL was almost $91.0 \% .^{16}$

The lower sensitivity in our series may be related to a smaller number of included B-NHL cases (only 32) as well as to a rather high percentage of germinal center (GC)/post-GC lymphomas which predominated in our group of B-NHLs (28 of 32, including 14 of $15 \mathrm{BM}$ aspirates taken for staging/ follow-up) (Table 2). It is namely well known that somatic mutations in the IGH gene are frequent in GC/post-GC B-cell lymphomas, especially in $\mathrm{FL}^{42}$, which contributes to a lower monoclonality 
rate. ${ }^{3,13,28,29}$ Indeed, all B-NHL cases with polyclonal IGH rearrangements in our study (8/32) were from the group of GC/post-GC lymphomas, including FL (3), marginal zone B-cell lymphoma (3), DLBCL (1) and B-cell lymphoma with features intermediate between the DLBCL and Burkitt (1).

The lower overall specificity of the IGH clonality assay in our series of NHL cases can be explained by the T-NHL entities in which monoclonal IGH rearrangements were detected: a case of T-cell lymphoma with monoclonal B-cell population and 3 specimens from a patient with angioimmunoblastic T-cell lymphoma (AITL). This is in concordance with the results from the BIOMED-2 study in which monoclonal IGH rearrangements were mostly detected in AITL (in $30.0 \%$ of cases) ${ }^{16}$ and also with the results of other studies where the presence of monoclonal IGH rearrangements in AITL was reported in $17.6 \%$ of cases. ${ }^{38}$ The fore mentioned studies have shown that monoclonal IGH gene rearrangements occur in $5-10 \%$ of all $\mathrm{T}$-cell malignancies and represent the so-called cross-rearrangements, which sometimes occur in more immature lymphoid cells. 3,16

Unlike in the T-NHL cases, the specificity of the IGH assay in our series of reactive lesions (87.2\%) is comparable to the results from the BIOMED-2 study. ${ }^{17}$ In our study, clearly polyclonal IGH products were determined in 41 of 49 reactive specimens (Table 1). In 6 cases, the monoclonal IGH products were detected - three BM aspirates taken for staging/follow-up of B-NHLs, two FFPE specimens suspective of lymphoma and one FNA specimen suspective of granulomatous lymphadenitis. A further pathological review of these cases did not show any cells suspective of B-cell lymphoma and were concluded as reactive lymphoproliferations. As previously stated, monoclonal results in reactive specimens must be interpreted with caution in the context of all clinical, morphological and immunophenotyping data. ${ }^{1,3}$ Concerning this, in all 6 cases a close follow-up and the re-sampling were recommended.

An important aspect of our study was the evaluation of the utility of reactions for the detection of incomplete rearrangements in the IGH gene, which can be detected in $\sim 30 \%$ of B-cell malignancies. ${ }^{3}$ In contrast to our expectations, among B-NHL cases (32) we detected only one incomplete rearrangement by the IGH-E reaction (3.1\%) - it was in case of FL, which was polyclonal in reactions targeting the complete rearrangements. Since histopathological diagnosis of this case was difficult, the detection of incomplete rearrangement might have served as an additional evidence of malignant process. The follow-up of this patient was strongly recommended. Considering the low frequency of incomplete rearrangements in all analyzed specimens of LP and the fact that only one additional monoclonal result was obtained in the group of B-NHLs we concluded that IGH-D and IGH-E reactions did not have any additional diagnostic value. Our results are in agreement with the study on 118 FFPE specimens from patients with FL, in which also no additional monoclonal results were detected with reactions targeting incomplete rearrangements (IGH-D and IGH-E). ${ }^{29}$

\section{BIOMED-2 TCR clonality assay}

The overall sensitivity of the TCR clonality assay in our diagnostic series was $91.9 \%$ which is in agreement with the reported sensitivity of the BIOMED-2/EuroClonality group (91.0\%). ${ }^{16}$ The TCRB clonality assay showed a higher analytical detection rate $(76.3 \%)$ than the TCRG clonality assay $(63.2 \%)$, which is in agreement with the results of the BIOMED-2 study. ${ }^{16}$

As we have previously shown for the IGH assay, the specificity of the TCR clonality assay in our study was lower than described by founders of the protocol. ${ }^{3,14}$ The determined specificity was $62.5 \%$ in the group of B-NHLs and $54.3 \%$ in the group of reactive lymphoid proliferations. However, the detection of monoclonal rearrangements in TCR genes in our series of B-NHL cases and reactive lesions is consistent with the findings from other studies, which have shown that the co-existing small T-cell populations are frequently present in both, B-cell malignancies and reactive specimens. ${ }^{15,17}$ The rearrangements in TCR genes occur in $10-20 \%$ of B-cell malignancies and are generally reported to be found in a single TCR locus. ${ }^{3,15}$ In contrast, we have detected multiple monoclonal results in TCRB and TCRG reactions in 5 cases of B-NHL. Interestingly, 4 of 5 specimens with monoclonal rearrangements in both TCRB and TCRG loci were BM aspirates taken for staging: MZL (2), FL (1) and DLBCL (1) (results not shown). One FNA specimen of initially suspected B-NHL with monoclonal rearrangements in both IGH and TCR genes was later reclassified as the T-cell lymphoma with a monoclonal B-cell population after an additional pathological examination of pleural fluid obtained from the same patient.

The unexpectedly high frequency $(43.5 \%)$ of monoclonal TCR rearrangements in reactive specimens in our study is difficult to explain (Table 3). 
It is well known that the $T c R \gamma$ gene has a restricted germline repertoire and a limited junctional diversity at the rearranged $\mathrm{V} \gamma-\mathrm{J} \gamma$ region, and thus theoretically carries the risk of pseudoclonal products in samples containing small numbers of T-cells. ${ }^{14}$ There is a possibility of detecting pseudoclonal products by the TCRG clonality assay in 4 of 20 cases, which were monoclonal by the TCRG clonality assay and polyclonal by the TCRB clonality assay. However, in 10 of 20 cases monoclonal TCR rearrangements were detected by both assays and can hardly be interpreted as pseudoclonal. It is of note that monoclonal TCR rearrangements in our cases with the final diagnosis of reactive lesions were mostly detected in BM aspirates (14/20 BM aspirates) (Table 3). The majority of $\mathrm{BM}$ aspirates with monoclonal TCR rearrangements (11/14) were taken for staging, all from patients initially suspective of having B-cell malignancies. Three specimens were taken for the assessment of minimal residual disease (MRD), the first from a patient with AITL, the second from a patient with plasmablastic lymphoma and the third from a patient with FL. All three were concluded as reactive BM specimens according to morphological and immunophenotyping data. However, it should be postulated that monoclonal TCR rearrangements might not always be clinically significant, since monoclonal T-cell populations can be detected in peripheral blood of the elderly, in patients with autoimmune diseases and in patients with viral infection. ${ }^{43-45}$

In the present study we confirmed the application value of standardized BIOMED-2 clonality assays for the detection of clonality in a routine diagnostic setting of non-Hodgkin's lymphomas. Our conclusions are that (i) three reactions for detection of complete IGH rearrangements and five reactions for detection of TCR rearrangements (targeting both TCRB and TCRG genes) are a good choice for the clonality testing in these lymphomas; (ii) reactions for the detection of incomplete $I G H$ rearrangements have not shown any additional diagnostic value in our hands; (iii) due to the lower sensitivity of the IGH clonality assay in our study, we should consider the introduction of the IGK clonality assay as an additional clonality test, especially in cases of GC/post-GC B-cell malignancies; (iv) detection of monoclonal rearrangements in both IGH and TCR genes must be interpreted with caution and in the context of all clinical, morphological and immunophenotyping data, as discussed elsewhere.

We are aware that our conclusions derive from a rather small diagnostic series of 121 specimens of different lymphoid proliferations with only 32 cases of confirmed B-NHLs and 38 cases of confirmed T-NHLs. Certainly, the evaluation of larger series of $\mathrm{B}$ and $\mathrm{T}$-cell lymphomas and reactive lesions needs to be done for firmer conclusions. Yet, we believe that our results might be useful for other laboratories aiming to introduce the standardized BIOMED-2 clonality assays in a routine laboratory practice.

\section{References}

1. Sandberg Y, van Gastel-Mol EJ, Verhaaf B, Lam KH, van Dongen JJ, Langerak AW. BIOMED-2 multiplex immunoglobulin/T-cell receptor polymerase chain reaction protocols can reliably replace Southern blot analysis in routine clonality diagnostics. J Mol Diagn 2005; 7: 495-503.

2. Hoeve MA, Krol AD, Philippo K, Derksen PW, Veenendaal RA, Schuuring $E$, et al. Limitations of clonality analysis of $B$ cell proliferations using CDR3 polymerase chain reaction. J Clin Pathol Mol Pathol 2000; 53: 194-200.

3. van Krieken JH, Langerak AW, Macintyre EA, Kneba M, Hodges E, Garcia Sanz $\mathrm{R}$, et al. Improved reliability of lymphoma diagnostics via PCR-based clonality testing: - Report of the BIOMED-2 concerted action BHM4-CT98-3936. Leukemia 2007; 21: 201-6.

4. McCarthy KP, Sloane JP, Wiedemann LM. Rapid method for distinguishing clonal from polyclonal B cell populations in surgical biopsy specimens. J Clin Pathol 1990; 43: 429-32.

5. Trainor KJ, Brisco MJ, Wan JH, Neoh S, Grist S, Morley AA. Gene rearrangement in B- and T-lymphoproliferative disease detected by the polymerase chain reaction. Blood 1991; 78: 192-5.

6. Slack DN, McCarthy KP, Wiedemann LM, Sloane JP. Evaluation of sensitivity, specificity and reproducibility of an optimized method for detecting clonal rearrangements of immunoglobulin and T-cell receptor genes in formalinfixed, paraffin-embedded sections. Diagn Mol Pathol 1993; 2: 223-32.

7. Segal GH, Jorgensen T, Masih AS, Braylan TC. Optimal primer selection for clonality assessment by polymerase chain reaction analysis: I. Low grade B-cell lymphoproliferative disorders of nonfollicular center cell type. Hum Pathol 1994; 25: 1269-75.

8. Davis TH, Courtland EY, Balk SP. Detection of clonal immunoglobulin gene rearrangements by polymerase chain reaction amplification and single-strand conformational polymorphism analysis. Am J Pathol 1993; 142: 1841-47.

9. Chen YT, Whitney KD, Chen Y. Clonality analysis of B-cell lymphoma in freshfrozen and paraffin-embedded tissues: The effects of variable polymerase chain reaction parameters. Mod Pathol 1994; 7: 429-34.

10. McCarthy KP, Sloane JP, Wiedemann LM. A simplified method of detection of clonal rearrangements of the T-cell receptor $g$ chain gene. Diagn $\mathrm{Mol}$ Pathol 1992; 1: 173-79.

11. Theodorou I, Raphael M, Bigorgne C, Fourcade C, Lahet C, Cochet G, et al Recombination pattern of the TCRg locus in human peripheral T-cell lymphomas. J Pathol 1994; 174: 233-42.

12. Diss TC, Watts $M$, Pan LX, Burke M, Linch D, Isaacson PG. The polymerase chain reaction in the demonstration of monoclonality in T cell lymphomas. J Clin Pathol 1995; 48: 1045-50.

13. Liu H, Bench AJ, Bacon CM, Payne K, Huang Y, Scott MA, et al. A practical strategy for the routine use of BIOMED-2 PCR assays for detection of B- and T-cell clonality in diagnostic haematopathology. Br J Haematol 2007; 138: 31-43.

14. van Dongen JJ, Langerak AW, Brüggemann $M$, Evans $P A$, Hummel $M$, Lavender FL, et al. Design and standardization of PCR primers and protocols for detection of clonal immunoglobulin and T-cell receptore gene recombinations in suspect lymphoproliferations: report of the BIOMED-2 Concerted Action BHM4-CT98-3936. Leukemia 2003; 17: 2257-317. 
15. Evans PA, Pott C, Groenen PJ, Salles G, Davi F, Berger F, et al. Significantly improved PCR-based clonality testing in B-cell malignancies by use of multiple immunoglobulin gene targets. Report of the BIOMED-2 Concerted Action BHM4-CT98-3936. Leukemia 2007; 21: 207-14.

16. Brüggemann $M$, White $H$, Gaulard P, Garcia-Sanz R, Gameiro P, Oeschger S, et al. Powerful strategy for polymerase chain reaction-based clonality assessment in T-cell malignancies. Report of the BIOMED-2 Concerted Action BHM4-CT98-3936. Leukemia 2007; 21: 215-21.

17. Langerak AW, Molina TJ, Lavender FL, Pearson D, Flohr T, Sambade C, et al. Polymerase chain reaction-based clonality testing in tissue samples with reactive lymphoproliferations: usefulness and pitfalls. A report of the BIOMED-2 Concerted Action BHM4-CT98-3936. Leukemia 2007; 21: 222-29.

18. Langerak AW, Groenen PJ, van Krieken JH, van Dongen JJ. Immunoglobulin/T cell receptor clonality diagnostics. Expert Opin Med Diagn 2007; 1: 451-61.

19. Groenen PJ, Langerak AW, van Dongen JJ, van Krieken JH. Pitfalls in TCR gene clonality testing: teaching cases. J Hematopathol 2008; 1: 97-109.

20. Matthews C, Catherwood M, Morris TC, Alexander HD. Routine analysis of IgHV mutational status in CLL patients using BIOMED-2 standardized primers and protocols. Leuk Lymphoma 2004; 45: 1899-904.

21. Dawidovska M, Jólkowska J, Sczepański T, Derwich K, Wachowiak J, Witt M Implementation of the standard strategy for identification of Ig/TCR targets for minimal residual disease diagnostics in B-cell precursor ALL pediatric patients: Polish experience. Arch Immunol Ther Exp 2008; 56: 409-18.

22. Chen YL, Su IJ, Cheng HY, Chang KC, Lu CC, Chow NH, et al. BIOMED-2 protocols to detect clonal immunoglobulin and T-cell receptor gene rearrangements in B- and T-cell lymphomas in southern Taiwan. Leuk Lymphoma 2010; 51: 650-55.

23. Lassmann S, Gerlach UV, Technau-Ihling K, Werner M, Fisch P. Application of BIOMED-2 primers in fixed and decalcified bone marrow biopsies: analysis of immunoglobulin $\mathrm{H}$ receptor rearrangements in B-cell non-Hodgkin's lymphomas. J Mol Diagn 2005; 7: 582-91.

24. Lukowsky A, Marchwat M, Sterry W, Gellrich S. Evaluation of B-cell clonality in archival skin biopsy samples of cutaneous B-cell lymphoma by immunoglobulin heavy chain gene polymerase chain reaction. Leuk Lymphoma 2006; 47: 487-93.

25. Hebeda KM, van Altena MC, Rombout P, van Krieken JH, Groenen PJ. PCR clonality detection in Hodgkin lymphoma. J Hematopathol 2009;2:34-41.

26. Burack WR, Laughlin TS, Friedberg JW, Spence JM, Rothberg PG. PCR assays detect B-lymphocyte clonality in formalin-fixed, paraffin-embedded specimens of classical Hodgkin lymphoma without microdissection. Am J Clin Pathol 2010; 134: 104-11.

27. Zhang S, Abreo F, Lowery-Nordberg M, Veillon DM, Cotelingam JD. The role of fluorescence in situ hybridization and polymerase chain reaction in the diagnosis and classification of lymphoproliferative disorders on fine-needle aspiration. Cancer Cytopathol 2010; 118: 105-12.

28. Payne K, Wright P, Grant JW, Huang Y, Hamoudi J, Bacon CM, et al. BIOMED-2 PCR assays for IGK gene rearrangements are essential for B-cell clonality analysis in follicular lymphoma. Br J Haematol 2011; 155: 84-92.

29. Berget E, Helgeland L, Molven A, Vintermyr OK. Detection of clonality in follicular lymphoma using formalin-fixed, paraffin-embedded tissue samples and BIOMED-2 immunoglobulin primers. J Clin Pathol 2011; 64: 37-41.

30. Sandberg Y, Heule F, Lam K, Lugtenburg PJ, Wolvers-Tettero IL, van Dongen $\mathrm{JJ}$, et al. Molecular immunoglobulin/T-cell receptor clonality in cutaneous lymphoproliferations. Experience with the BIOMED-2 standardized polymerase chain reaction protocol. Haematologica 2003; 88: 659-70.

31. Catherwood MA, Gonzales D, Patton C; Dobbin E, Venkatraman L, Alexander $\mathrm{HD}$. Improved clonality assessment in germinal centre/post germinal centre non- Hodgkin's lymphomas with high rates of somatic hypermutation. J Clin Pathol 2007; 60: 524-28.

32. Tan BT, Seo K, Warnke RA, Arber DA. The frequency of immunoglobulin heavy chain gene and T-cell receptor g-chain gene rearrangements and Epstein-Barr virus in ALK+ and ALK- anaplastic large cell lymphoma and other peripheral T-cell lymphomas. J Mol Diagn 2008; 10: 502-12.

33. Zhang B, Beck AH, Taube JM, Kohler S, Seo K, Zwerner J, et al. Combined use of PCR-based TCRG and TCRB clonality tests on paraffin-embedded skin tissue in the differential diagnosis of Mycosis fungoides and inflammatory dermatoses. J Mol Diagn 2010; 12: 320-27.
34. Nakamichi N, Wada N, Kohara M, Fukuhara S, Sugiyama H, Ogawa H, et al. Polymorphous lymphoproliferative disorder: a clinicopathological analysis. Virchows Arch 2010; 456: 269-76.

35. Dabiri S, Morales A, Ma L, Sundram U, Kim YH, Arber DA, et al. The frequency of dual TCR-PCR clonality in granulomatous disorders. J Cutan Pathol 2011; 38: 704-9.

36. McClure RF, Kaur P, Pagel E, Ouillette PD, Holtegaard CE, Treptow $C L$, et al. Validation of immunoglobulin gene rearrangement detection by PCR using commercially available BIOMED-2 primers. Leukemia 2006; 20: 176-79.

37. Patel KP, Pan Q, Wang Y, Maitta RW; Du J, Xue $X$, et al. Comparison of BIOMED-2 versus laboratory-developed polymerase chain reaction assays for detecting T-cell receptor-g gene rearrangements. J Mol Diagn 2010; 12 226-37.

38. Zaki MA, Wada N, Kohara M, Ikeda J, Hori Y, Fujita S, et al. Presence of B-cell clones in T-cell lymphoma. Eur J Haematol 2011; 86: 412-19.

39. Langerak AW, Groenen PJ, Brüggemann M, Beldjord K, Bellan C, Bonello L, et al. EuroClonality/BIOMED-2 guidelines for interpretation and reporting of $\mathrm{Ig} / \mathrm{TCR}$ clonality testing in suspected lymphoproliferations. Leukemia 2012; 26: 2159-71.

40. Jaffe ES, Harris NL, Stein $\mathrm{H}$ and Vardiman JW: Tumours of Haematopoietic and Lymphoid Tissues. In: World Health Organization Classification of Tumours. Lyon: IARC Press; 2001.

41. Swerdlow SH, Campo E, Harris NL, Jaffe ES, Pileri SA, Stein H, et al. WHO Classification of Tumors of Haematopoietic and Lymphoid Tissues. Lyon:IARC Press; 2008.

42. Diss TC, Peng H, Wotherspoon AC, Isaacson PG, Pan L. Detection of monoclonality in low-grade B-cell lymphomas using the polymerase chain reaction is dependent on primer selection and lymphoma type. J Pathol 1993, 169: 291-95.

43. Posnett DN, Sinha R, Kabak S, Russo C. Clonal populations of T cells in normal elderly humans: the T cell equivalent to "benign monoclonal gammapathy". J Exp Med 1994; 179: 609-18.

44. Delfau-Larue MH, Laroche L, Wechsler J, Lepage E, Lahet C, Asso-Bonnet $M$, et al. Diagnostic value of dominant T-cell clones in peripheral blood in 363 patients presenting consecutively with a clinical suspicion of cutaneous lymphoma. Blood 2000; 96: 2987-92.

45. Godges E, Krishna MT, Pickard C, Smith JL. Diagnostic role of test for T cell receptor (TCR) genes. J Clin Pathol 2003; 56: 1-11. 